J. Dairy Sci. 92:749-757

doi:10.3168/jds.2008-1356

(c) American Dairy Science Association, 2009.

\title{
Differences in udder health and immune response traits of Holstein- Friesians, Norwegian Reds, and their crosses in second lactation
}

\author{
N. Begley, ${ }^{*}$ F. Buckley, ${ }^{* 1}$ K. M. Pierce, $†$ A. G. Fahey, $†$ and B. A. Mallard‡ \\ ${ }^{*}$ Teagasc, Dairy Production Research Centre, Moorepark, Fermoy, Co. Cork, Ireland \\ †School of Agriculture, Food and Veterinary Medicine, University College Dublin, Belfield, Dublin 4, Ireland \\ łDepartment of Pathobiology, Ontario Veterinary College, University of Guelph, Guelph, Ontario, Canada N1G 2W1
}

\section{ABSTRACT}

The objective of this study was to investigate potential differences in udder health and immune response traits among Holstein-Friesian (HF), Norwegian Red $(\mathrm{NR})$, and $\mathrm{NR} \times \mathrm{HF}(\mathrm{NRX})$ cows on 30 commercial Irish dairy farms. A total of 648 second-lactation cows $(\mathrm{HF} \mathrm{n}=274, \mathrm{NR} \mathrm{n}=207$, and NRX $\mathrm{n}=167)$ were immunized with hen egg white lysozyme (HEWL) to induce antibody-mediated immune response (AMIR). Candida albicans was used to induce a cell-mediated immune response, with in vivo delayed-type hypersensitivity used as the indicator. Antibody response to HEWL was measured by ELISA. Udder health defined as mean somatic cell score (SCS) over the lactation, mean SCS within $30 \mathrm{~d}$ of the beginning of the immunization, peak SCS for each individual cow during lactation, and incidence of mastitis were statistically superior for the NR. The NR had a greater primary AMIR, producing greater concentrations of anti-HEWL immunoglobulin G on d 14 compared with HF and NRX. No difference was observed among the breed groups in the magnitude of secondary AMIR (d 21 post-immunization) or cell-mediated immune response. The proportion of high and low responders was similar across breed groups. Cows with high AMIR and high cell-mediated immune response had significantly lower mean SCS within 30 $\mathrm{d}$ of the start of the immunization, but greater occurrence of clinical mastitis, recorded as a binary trait over the course of the lactation. Otherwise, no significant difference in udder health was evident between cows designated as high and low responders. Although differences in mean breed group SCS values were in line with group mean AMIR values, no association was found among the traits when correlated on an individual cow basis. Results highlight the superiority of the NR with regard to udder health and suggest that improvements to udder health may result from crossbreeding with the

Received May 13, 2008.

Accepted September 15, 2008.

${ }^{1}$ Corresponding author: frank.buckley@teagasc.ie
NR. However, the immune response traits investigated proved to be inconsistent indicators of udder health. Key words: Norwegian Red, udder health, crossbreeding, immune response

\section{INTRODUCTION}

The prevalence of mastitis and high SCC on dairy farms is an issue that concerns both the dairy farmer and the milk processor. The costs incurred as a result of mastitis and SCC have been well documented (Auldist et al., 1995; Berry et al., 2005; Berry and Amer, 2005). In Ireland, the incidence of mastitis is assumed to be approximately $25 \%$ per year, with a mild case costing approximately €45.31 and a severe case $€ 185.56$ (Berry and Amer, 2005). In Ireland penalties are imposed on milk with high SCC (>400,000 cells/mL) based on a tiered monthly arithmetic mean bulk SCC. Moreover, some processors have introduced bonus schemes for herds achieving bulk SCC of 200,000 cells/mL or less. Therefore, the onus lies with producers to keep mastitis cases and SCC increases to a minimum.

Genetic correlations in the order of 0.25 to 0.45 have been estimated between clinical mastitis and milk yield (Heringstad et al., 1999; Rupp and Boichard, 1999). Aggressive selection for milk production over the years with little or no emphasis on functional traits (Miglior et al., 2005) has been linked to a decline in udder health (Hansen et al., 2002; Heringstad et al., 2003). In 2001, a new selection index, the Economic Breeding Index, was introduced in Ireland (Berry and Amer, 2005). Since launch of this index, traits reflecting key determinants of dairy cow profitability, including fertility and health traits, have been incorporated into the index.

The breeding program of the Norwegian Red (NR) dairy breed is well known for its broad selection goals. In Norway, the total merit index philosophy has been implemented for almost 5 decades (Heringstad et al., 2000). Accurate recording and selection against clinical mastitis since 1978 has contributed to a lower incidence of clinical mastitis in the national population (Heringstad et al., 2003). 
To ensure that the best indicators of health traits are included in breeding programs, research is ongoing into the identification of various alleles and genetic markers that may enhance disease resistance through their inclusion as indicator traits. However, the majority of infectious diseases and common groups of pathogens are generally controlled by more than one gene (Mallard et al., 1995; Wilkie and Mallard, 1999). Therefore, a broad-based approach may be more appropriate. The potential benefits of using antibody-mediated immune response (AMIR) and cell-mediated immune response (CMIR) as an aid for improving host defense has been recognized for mice (Biozzi et al., 1979), chickens (Pinard et al., 1993), and pigs (Mallard et al., 1992). Studies have also indicated that sufficient genetic variation exists to breed for AMIR and CMIR (Wilkie and Mallard, 1999; Mallard, 2007). Wagter et al. (2003) showed that in 2 out of 3 herds tested, lower incidences of mastitis were observed in high antibody responders. Heritability estimates of 0.37 and 0.41 have been reported (Hernandez et al., 2006) for AMIR and CMIR, respectively. However, because of a negative genetic correlation between AMIR and CMIR, identification of animals that are high responders for both traits is imperative (Mallard et al., 1992; Hernandez et al., 2006) to maintain a balanced immune response (IR).

Research at Teagasc Moorepark (Ireland) demonstrated that the NR breed has superior udder health (Walsh et al., 2007) and reproductive efficiency (Walsh et al., 2008). Consequently, a larger on-farm study involving 46 commercial dairy farms was established to conclusively evaluate the merits of the NR breed and determine the potential suitability of crossbreeding with the NR as a breeding strategy for Irish dairy farmers. An important aim of the study was to generate data that could be used by the Irish Cattle Breeding Federation (ICBF) to provide breeding value estimates for the NR breed in Ireland through an across-breed evaluation. As part of this study Holstein-Friesian (HF), NR, and Norwegian Red $\times$ Holstein-Friesian $(\mathbf{N R X )}$ cows were available. Given the contrasting selection history and previously reported udder health differences (Walsh et al., 2007) between the $\mathrm{HF}$ and the NR, it was considered relevant to investigate if differences exist between the breeds for AMIR and CMIR. This study provided a unique opportunity to investigate if such differences do exist among the breeds and their cross and to determine if associations between IR traits and udder health are apparent.

\section{MATERIALS AND METHODS}

\section{Animal Data Set and Immunization Procedures}

Immune response was evaluated on 648 secondlactation dairy cows $(\mathrm{HF} \mathrm{n}=274 ; \mathrm{NR} \mathrm{n}=207$; and
NRX $\mathrm{n}=167$ ) across 30 Irish dairy farms (a subset of the 46 farms participating in the more expansive study; Begley et al., 2007a). With the exception of 2 herds, which had HF and NR cows only, all herds had cows of each breed group. All farms on the study were participants of the Dairy Management Information System at Teagasc Moorepark. The Dairy Management Information System is a recorder-based computerized database, where detailed information regarding stock, farm inputs, and production events are recorded on a regular basis. Cows had calved on average $158 \mathrm{~d}( \pm 33$ d) before the beginning of the immunization procedure (i.e., only non-periparturient cows were used in this study). The NR and NRX cows were sired by a total of 10 proven NR sires. The HF cows were sired by a total of 56 sires of North American HF, New Zealand Friesian, and British Friesian genetics. These included 45 sires of North American HF genetics and 11 sires from New Zealand Friesian and British Friesian genetics. The HF and NRX cows were born on the study farms, whereas the NR cows were imported from Norway in 2004 as calves and reared on the study farms alongside their HF and NRX contemporaries.

The 2 measurements of IR in this study were AMIR and CMIR. Antibody-mediated immune response is the key determinant in the control of extracellular pathogens, whereas CMIR dominates in the control of intracellular pathogens. Together they are measurements of broad-based immunity. Cows were immunized during July to October 2007 to induce AMIR and delayedtype hypersensitivity (DTH) as described previously by Wagter et al. (2000) and Hernandez et al. (2003). Briefly, cows received hen egg white lysozyme (HEWL, 0.5 mg; Sigma, Dublin, Ireland) intramuscularly, along with the DTH-inducing antigen, Candida albicans (0.5 mg, Greer Laboratories, Hornby, Ontario, Canada), in QuilA adjuvant (0.5 mg, Brenntagg, Denmark) combined in a total volume of $1.0 \mathrm{~mL}$ of PBS ( $\mathrm{pH} 7.4)$ on d 0 and 14. Blood samples were collected by caudal venipuncture on d 0 (baseline), 14 (primary response), and 21 (secondary response). Serum was derived from the blood samples each day and stored at $-20^{\circ} \mathrm{C}$.

As an in vivo indicator of CMIR, DTH was carried out following previously described protocols (Hernandez et al., 2005). A previous Canadian study by Hernandez et al. (2006) estimated heritability of this trait to be 0.40 and also determined minimal preexisting antibody against $C$. albicans demonstrating its usefulness as a DTH test antigen. Briefly, 2 sites were shaved behind the shoulder to prepare for immunization. Background skin thickness measurements were taken on d 21 (3 replicates) behind the shoulder using a McClintoch skin callipers (Acrvet Kanturk, Co. Cork, Ireland). The DTH response was subsequently elicited using the in- 
tradermal skin test as follows: animals were immunized with $0.1 \mathrm{mg}$ of $C$. albicans dissolved in $0.1 \mathrm{~mL}$ of PBS behind the shoulder; as a control, $0.1 \mathrm{~mL}$ of PBS was injected approximately 1 inch below the test site. An increase in double skin-fold thickness was indicative of the magnitude of DTH when measurements were taken at the control and test antigen sites after $48 \mathrm{~h}$ (d 23). This has been shown to be the optimal time to achieve maximum response (Hernandez et al., 2005) Values were expressed as an increase in thickness $(\mathrm{mm})$ from 0 to $48 \mathrm{~h}$, while accounting for any increases at the control injection site:

$$
\text { Increase }(\mathrm{mm})=(\mathrm{A}-\mathrm{B})-(\mathrm{C}-\mathrm{D}) \text {, }
$$

where $\mathrm{A}=$ mean test thickness (at time $=48 \mathrm{~h}$ ), $\mathrm{B}=$ mean of pretest thickness (at time $=0 \mathrm{~h}$ ), $\mathrm{C}=$ mean of control thickness (at time $=48 \mathrm{~h}$ ) and $\mathrm{D}=$ mean of precontrol thickness (at time $=0 \mathrm{~h}$ ).

\section{Serum Antibody}

Antibody response to HEWL was measured using a previously described ELISA method (Wagter et al., 2000). Sera, including negative and positive control samples (to be used as standards on each plate), were diluted at 1:50 and 1:300 in PBS and 0.05\% Tween 20 (Sigma) wash buffer (pH 7.4). Serum samples were measured in duplicate allowing 20 samples to be analyzed per plate. Rabbit anti-bovine $\operatorname{IgG}$ was used at a dilution of 1:8,000. Negative and positive controls were obtained by pooling samples of sera from cows preimmunization ( $\mathrm{d} 0$ ) and from sera post-immunization (d 21), respectively, and were used as controls for each assay. Antibody concentration was estimated by optical density (OD) using an automatic ELISA plate reader (EL311, Mason Technology, Dublin, Ireland). The OD was recorded at 405 and $630 \mathrm{~nm}$ when the positive control reached OD $\geq 0.999$. Values were corrected to an $\mathrm{OD}=1.0$ as described previously (Wagter et al., 2000). To maintain unity among assays, samples were reanalyzed if the CV of the positive and negative samples on the plate were greater than $15 \%$. If duplicate serum samples on the plate had a CV of greater than $15 \%$, they were also reanalyzed.

\section{Health Data}

Cows' milk weights were recorded and samples collected a minimum of 3 times during lactation (averaged $5.41 \pm 2.01$ times). Individual test-day milk production and SCC records were obtained from the ICBF, with 305-d predicted yields derived using the standard lactation curve method (Olori and Galesloot, 1999). The SCC data were transformed to SCS using $\log _{10}$ transformation for normalization of the residuals (Green et al., 2004). Five variables reflecting the udder health status of each cow were created. These included the mean of all available SCS records over lactation (SCSAV), the mean of SCS records within $\pm 30 \mathrm{~d}$ of the start of the immunization procedure (SCSIR), the peak SCS record for each individual cow during lactation (SCSH), and the occurrence of clinical mastitis (MAST; available for 27 of the 30 farms). One or more mastitis incidences were recorded as one occurrence for the purposes of the analyses. A binary variable was also created as an indicator of subclinical mastitis. This was defined as at least one SCC record $>400,000$ cells $/ \mathrm{mL}$ (SCC400). This threshold was chosen because Irish dairy farmers are penalized if average monthly SCC is $>400,000$ cells $/ \mathrm{mL}$.

\section{Statistical Analyses}

Data were checked for normality and homogeneity of variance using histograms, qqplots, and formal statistical tests in the UNIVARIATE procedure (version 9.1.3; SAS Institute, 2006). Data that were not normal were transformed by raising the variable to the power of lambda. The appropriate lambda value was obtained by conducting a Box-Cox transformation analysis in the TRANSREG procedure in SAS. Immunoglobulin (IgG) data on d 0 were transformed using a lambda value of $-0.25, \operatorname{IgG}$ on d 14 was given a $\log _{10}$ transformation, and IgG on d 21 and primary and secondary responses were transformed using a lambda value of 0.25 . Primary response was defined in 2 parts: 1 ) the concentration of anti-HEWL on d 14, and 2) the percentage increase in anti-HEWL IgG production from d 0 to 14. Similarly, secondary response was evaluated as the concentration of anti-HEWL IgG on d 21 and the percentage increase in anti-HEWL IgG production from d 14 to 21 (Wagter et al., 2000). The transformed data was used to calculate $P$-values. However, the corresponding least squares means and standard errors of the nontransformed data are presented in the results for clarity. An ANOVA was conducted using GLM with a Tukey adjustment for multiple comparisons (SAS Institute, 2006). The following model was used:

$$
\mathrm{Y}_{\mathrm{ijkl}}=\mu+\operatorname{Herd}_{\mathrm{j}}+\text { Breed }_{\mathrm{k}}+\text { Calving date }_{\mathrm{l}}+\mathrm{e}_{\mathrm{ijk} \mathrm{k}} \text {, }
$$

where $Y_{i j k}=$ the observed values for 305-d milk and composition, IgG on d 0, 14, and 21, primary and secondary IR, and DTH for the $i$ th cow, in the $j$ th herd of the $k$ th breed with the $l$ th calving date; Herd $_{\mathrm{j}}=$ fixed 
Table 1. Least squares means of the effect of Holstein-Friesian (HF), Norwegian Red (NR), and Norwegian Red $\times$ Holstein-Friesian (NRX) breed group on milk production and udder health

\begin{tabular}{|c|c|c|c|c|c|}
\hline \multirow[b]{2}{*}{ Item $^{1}$} & \multicolumn{3}{|c|}{ Breed } & \multirow[b]{2}{*}{$\mathrm{SE}$} & \multirow[b]{2}{*}{$P$-value } \\
\hline & $\mathrm{HF}$ & NR & NRX & & \\
\hline 305-d Protein (\%) & 3.48 & 3.48 & 3.47 & 0.020 & $\mathrm{NS}^{2}$ \\
\hline 305-d Fat $(\%)$ & 3.98 & 3.93 & 3.94 & 0.035 & NS \\
\hline Fat + protein $(\mathrm{kg})$ & 454 & 419 & 436 & 5.3 & $<0.01$ \\
\hline SCSAV & $2.15^{\mathrm{a}}(223,000)^{3}$ & $2.04^{\mathrm{b}}(174,000)$ & $2.12^{\mathrm{a}}(202,000)$ & 0.024 & $<0.01$ \\
\hline MAST (\%) & $11.9^{\mathrm{a}}$ & $6.0^{\mathrm{b}}$ & $10.4^{\mathrm{a}}$ & 1.9 & $<0.05$ \\
\hline SCC400 (\%) & 9.03 & 8.96 & 9.29 & 2.0 & NS \\
\hline
\end{tabular}

${ }^{\mathrm{a}-\mathrm{c}}$ Means within a row with different superscripts differ $(P<0.05)$

${ }^{1}$ SCSAV = mean of all available SCS records over lactation; SCSH = peak SCS record during lactation; SCSIR = mean of SCS records within $\pm 30 \mathrm{~d}$ of the start of the immunization procedure; MAST = occurrence of at least 1 case of clinical mastitis during lactation; SCC400 = percentage of cows with at least 1 test $>400,000$ cells/mL during lactation.

${ }^{2} \mathrm{NS}=P>0.05$.

${ }^{3}$ Corresponding SCC (cells $\left./ \mathrm{mL}\right)$.

effect of herd $\mathrm{j}(\mathrm{j}=1$ to 30$) ;$ Breed $_{\mathrm{k}}=$ fixed effect of $k$ th breed (where $k=\mathrm{HF}, \mathrm{NR}$, or NRX); Calving date $=$ fixed effect of calving date $k$ of the $j$ th cow; and $\mathrm{e}_{\mathrm{ijkl}}$ $=$ residual error.

The MAST and SCC400 variables had a binomial distribution, so a logistical regression analysis with herd, breed, and calving date treated as fixed effects was conducted using the LOGISTIC procedure (SAS Institute, 2006).

Spearman product moment correlations of IR with the various indicators of udder health status were calculated using the PROC CORR procedure (SAS Institute, 2006). Within the IR variables, high responders were defined as cows that exhibited IR values 1 standard deviation (SD) above the mean value for all cows, and low responders were defined as cows that exhibited IR values $1 \mathrm{SD}$ below the mean value (Hernandez et al., 2005). These values were estimated using the residuals from the model (observations minus estimated effects for herd and breed). Differences in the proportion of high and low responders among breed groups were compared using Chi-square analysis. Analyses to determine if differences in udder health were evident between high and low responders were investigated using the Student's $t$-test.

\section{RESULTS}

\section{Milk Production and Udder Health}

The effect of breed group on milk production and udder health are presented in Table 1. Milk yield (305 d) was greatest for $\mathrm{HF}(6,134 \mathrm{~kg})$ and lowest for NR $(5,665 \mathrm{~kg})$. That of NRX $(5,960 \mathrm{~kg})$ was significantly lower $(P<0.05)$ than for HF, but greater $(P<0.001)$ compared with NR. Milk composition (fat and protein content) did not differ significantly among the breed groups. Yields of fat and protein were greatest for HF $(454 \mathrm{~kg})$ and lowest for NR $(419 \mathrm{~kg})$, whereas that of NRX $(436 \mathrm{~kg})$ was lower $(P<0.01)$ compared with HF and greater compared with NR $(P<0.01)$.

Udder health characterized as SCSAV, SCSIR, SCSH, and MAST was significantly favorable for the NR compared with the HF or NRX cows. Mean SCSAV values of $2.15,2.04$, and 2.12 were obtained with the HF, NR, and NRX cows, corresponding to mean SCC values throughout lactation of 223,000, 174,000 and 202,000 cells/mL, respectively. Similarly, NR had the lowest SCSIR at 1.97 equating to 170,000 cells $/ \mathrm{mL}$, with that of the HF greater $(P<0.001)$ at 2.10 or 244,000 cells/ $\mathrm{mL}$ and the NRX at 2.07 or 186,000 cells $/ \mathrm{mL}(P<$ 0.01 ). The SCSH was again lowest for the NR at an SCS of 2.27, compared with HF, which had the greatest $(P<0.05)$ at 2.35 . That of NRX was similar to HF at 2.33 , but not significantly greater than that of NR. Corresponding SCC values were 422,000, 359,000, and 402,000 cells/mL for HF, NR, and NRX, respectively. Although the findings in relation to SCC400 were directionally similar to SCSAV, SCSH, and SCSIR (i.e., favorable for NR), the differences observed among the breed groups were not significant. The proportion of cows that developed mastitis, however, was lower $(P$ $<0.05)$ for NR $(6 \%)$ compared with $\mathrm{HF}(11.9 \%)$ and NRX $(10.4 \%)$ cows.

\section{Anti-HEWL Total IgG Antibody}

The concentration of anti-HEWL IgG antibody measured on d 0 was not different among the breeds groups (Table 2). Mean OD values of $0.24( \pm 0.096), 0.23$ 
Table 2. Least squares means of the effect of Holstein-Friesian (HF), Norwegian Red (NR), and Norwegian Red $\times$ Holstein-Friesian (NRX) breed group on the production of anti-hen egg white lysozyme (anti-HEWL) IgG antibody expressed as optical density values, percentage increase in primary and secondary responses, and delayed-type hypersensitivity (DTH) measured as millimeter increase in double skin-fold thickness after $48 \mathrm{~h}$

\begin{tabular}{|c|c|c|c|c|c|}
\hline \multirow[b]{2}{*}{ Item } & \multicolumn{3}{|c|}{ Breed } & \multirow[b]{2}{*}{ SE } & \multirow[b]{2}{*}{$P$-value } \\
\hline & $\mathrm{HF}$ & NR & NRX & & \\
\hline \multicolumn{6}{|l|}{ Anti-HEWL IgG } \\
\hline d 0 & 0.24 & 0.23 & 0.23 & 0.006 & $\mathrm{NS}^{1}$ \\
\hline d 14 & $0.45^{\mathrm{a}}$ & $0.50^{\mathrm{b}}$ & $0.46^{\mathrm{a}}$ & 0.014 & $<0.01$ \\
\hline d 21 & 0.94 & 0.98 & 0.96 & 0.021 & NS \\
\hline Primary response ${ }^{2}(\%)$ & $100^{\mathrm{a}}$ & $135^{\mathrm{b}}$ & $122^{\mathrm{a}}$ & 8.2 & $<0.01$ \\
\hline Secondary response $^{3}(\%)$ & 143 & 146 & 148 & 9.2 & NS \\
\hline $\mathrm{DTH}(\mathrm{mm})$ & 8.1 & 7.9 & 8.1 & 0.28 & NS \\
\hline
\end{tabular}

$( \pm 0.095)$, and $0.23( \pm 0.095)$ were obtained for the HF, NR, and NRX cows, respectively. On d 14, differences in the production of anti-HEWL IgG were observed. Concentrations of anti-HEWL IgG were decreased $(P$ $<0.01)$ with the HF at $0.45( \pm 0.23)$ with a range of values from 0.11 to 1.09 , compared with the NR with a mean OD value of $0.50( \pm 0.23)$ ranging from 0.16 to 1.8. The NRX had an OD value of $0.46( \pm 0.23)$, ranging from 0.14 to 1.41 , which was also lower $(P<0.05)$ than the NR. The CV were $2.7,3.2$, and $3.4 \%$ for $\mathrm{HF}$, NR, and NRX, respectively.

The primary response when expressed as the percentage increase in production of anti-HEWL IgG from $d$ 0 to d 14 was greatest for the NR at $135 \%( \pm 129)$ with a CV of $6.6 \%$. The lowest primary response was observed with the $\mathrm{HF}$ at $100 \%( \pm 102)$ with a $\mathrm{CV}$ of $6.0 \%$, significantly less $(P<0.05)$ than that observed with the NR. There was a tendency $(P=0.06)$ for the NRX cows to produce a greater primary response at $122 \%( \pm 156)$ with a CV of $10 \%$, compared with the HF cows. Eighteen cows did not elicit a primary response [10 (3.6\%) HF, $2(0.9 \%) \mathrm{NR}$, and $6(3.5 \%)$ NRX cows]. Reanalysis of the data excluding nonresponders did not alter the results.

No differences were observed among the breed groups for production of anti-HEWL IgG on d 21 but the breed rank remained NR $>$ NRX $>$ HF. Mean OD values of $0.94( \pm 0.23), 0.98( \pm 0.32)$, and $0.96( \pm 0.38)$ were obtained for the HF, NR, and NRX cows, respectively. Secondary response described as the percentage increase in production of anti-HEWL IgG from d 14 to 21 observed were $143 \%$ ( \pm 126$), 146 \%$ ( \pm 143$)$, and $148 \%( \pm 140)$ for HF, NR, and NRX, respectively, with corresponding CV of 5.4, 7.5, and 7.1\%. Nonresponders included $11(4.0 \%) \mathrm{HF}, 7(3.4 \%) \mathrm{NR}$, and $8(4.8 \%)$
NRX cows. Again, reanalysis excluding nonresponders did not alter the results.

\section{Cell-Mediated Antibody Response}

No significant differences were observed between breed groups for DTH response (Table 2). A double skin-fold increase of $8.1 \mathrm{~mm}( \pm 0.34), 7.9 \mathrm{~mm}( \pm 0.33)$, and $8.1 \mathrm{~mm}( \pm 0.35)$ with ranges from 1.6 to $18.6 \mathrm{~mm}$ (CV of $2.5 \%$ ), 2.6 to $20.3 \mathrm{~mm}$ (CV of $2.8 \%$ ), and 2.6 to $25.6 \mathrm{~mm}$ (CV of $3.3 \%$ ) were obtained for $\mathrm{HF}, \mathrm{NR}$, and NRX cows, respectively.

\section{High and Low Immune Responders}

Table 3 reports the proportion of high and low responders identified among the breed groups. No differences were observed among any of the breed groups for high and low responders. In addition to this, no cow was identified as having a high IR for all 3 traits investigated. There was $1 \mathrm{HF}, 1 \mathrm{NR}$, and no NRX observed as low responders for all 3 traits.

\section{Associations of Immune Response Variables with Udder Health}

When analysis was carried out across the entire data set (all breeds combined), no association between the IR variables investigated (neither the concentration of antibody on d 14 or 21, nor the primary or secondary responses) and the various measurements of udder health were detected using the Spearman correlation. When analysis was carried out within breed, a negative correlation of $-0.13(P<0.05)$ was observed between the production of anti-HEWL IgG on d 21 and SCSIR 
Table 3. Least squares means of the effect of Holstein-Friesian (HF), Norwegian Red (NR), and Norwegian Red $\times$ Holstein-Friesian (NRX) breed group on the proportion of high and low responders defined as 1 SD above and below the mean, respectively

\begin{tabular}{lcccc}
\hline & \multicolumn{3}{c}{ Breed } & \\
\cline { 2 - 3 } Item $^{1}$ & HF & NR & NRX & P-value \\
\hline High responders & & & & \\
Anti-HEWL IgG d 14 (\%) & 16.1 & 16.0 & 13.6 & NS $^{2}$ \\
Anti-HEWL IgG d 21 (\%) & 9.9 & 12.1 & 10.1 & NS \\
DTH (\%) & 14.6 & 15.1 & 9.5 & NS \\
Anti-HEWL IgG d 14 + DTH (\%) & 2.93 & 1.94 & 2.37 & NS \\
Anti-HEWL IgG d 21 + DTH (\%) & 0.37 & 1.94 & 0.59 & NS \\
Low responders & 12.8 & 14.1 & 10.7 & NS \\
Anti-HEWL IgG d 14 (\%) & 12.1 & 9.22 & 13.6 & NS \\
Anti-HEWL IgG d 21 (\%) & 15.7 & 9.18 & 14.4 & NS \\
DTH (\%) & 1.83 & 0.97 & 0.59 & NS \\
Anti-HEWL IgG d 14 + DTH (\%) & 0.73 & 1.46 & 1.18 & NS \\
Anti-HEWL IgG d 21 + DTH (\%) & & & & \\
\hline
\end{tabular}

${ }^{1}$ Anti-HEWL IgG = anti-hen egg white lysozyme IgG antibody; DTH = delayed-type hypersensitivity measured as millimeter increase in double skin-fold thickness after $48 \mathrm{~h}$.

${ }^{2} \mathrm{NS} P>0.05$.

for the HF. In other words, high secondary antibody was weakly associated with lesser SCS during the time of IR testing. With the NR there was a tendency $(P=$ $0.06)$ for a negative correlation of a similar level $(-0.13)$ between anti-HEWL IgG on d 0 and SCSH.

Mastitis incidence was unfavorably associated $(P=$ 0.02 ) with cows ranked high for a combination of AMIR on d 14 and DTH. However, these differences were inconsistent because there were no differences in mastitis between high or low responders for the combination of AMIR on d 21 and DTH (Table 4). It was observed that SCSIR was lower $(P=0.06)$ for high responders compared with low responders based on AMIR at $d$ 21 and DTH, but these results were also inconsistent because differences were not apparent based on AMIR at d 14 and DTH or for SCS at other time points (Table $4)$.

\section{DISCUSSION}

The objective of this study was to investigate potential differences in udder health and IR among HF, NR, and crossbred dairy cows generated by mating NR sires to HF cows. A further objective was to evaluate if associations existed between IR and measures of udder health. In general, udder health as characterized by SCC and incidence of clinical mastitis across the 30 study herds was excellent. Nonetheless, clear breed differences with respect to udder health in favor of the NR breed were observed within this study. This is in keeping with the previous findings of Walsh et al. (2007), although that study involved a smaller number of cows. The findings of both studies highlight the benefits of a well-balanced breeding program. Selection against clinical mastitis has been part of the Norwegian breeding program since 1978 (Heringstad et al., 2000). Although the NR and NRX cows in the current study were sired by a limited number of NR sires $(n=10)$, the mean breeding value for mastitis resistance of these sires was breed average for the trait at 101 (Geno Norway, June 2008). The HF cows were sired by a relatively large number of sires $(\mathrm{n}=56)$ and are therefore representative of $\mathrm{HF}$ in Ireland.

Superior primary AMIR was observed for NR compared with both HF and NRX. A stronger primary response might be suggestive of a greater ability to combat initial infection or challenge, particularly against extracellular pathogens. A study undertaken previously on Canadian commercial dairy farms illustrated that NRX calves 2 to 6 mo old displayed a greater primary response compared with Holstein calves (Begley et al., $2007 b)$. In the current study there was a tendency ( $P$ $<0.06)$ for the NRX to have a greater primary antibody response compared with HF. The NRX also had a greater secondary response compared with the HF, but this difference was not significant. Begley et al. (2007b) found no significant difference between breed groups in the production of secondary IgG measured on d 21 . This may suggest a similar capability for immunological memory among the breeds.

Results from the current study indicated that there were no differences in CMIR, which is concurrent with the results observed in the previous study by Begley et al. (2007b) using calves. A noteworthy point regarding DTH is that in both studies, even though it was not significant, the breed ranking was HF > NRX. This may not be surprising, however, given the often opposing relationship between AMIR and CMIR (Hernandez et 
Table 4. Least squares means of the effect of high and low responders for the production of anti-hen egg white lysozyme (anti-HEWL) IgG antibody on d 14 and 21 and delayed-type hypersensitivity (DTH, measured as $\mathrm{mm}$ increase in skin-fold thickness at $48 \mathrm{~h}$ ) on udder health traits

\begin{tabular}{lcccc}
\hline Item $^{1}$ & High & Low & SE & $P$-value \\
\hline Anti-HEWL IgG d 14 and DTH & & & & \\
SCSAV & $2.15(203,000)^{2}$ & $2.21(252,000)$ & 0.06 & $\mathrm{NS}^{3}$ \\
SCSIR & $2.09(246,000)$ & $2.08(175,000)$ & 0.10 & $\mathrm{NS}$ \\
SCSH & $2.45(503,000)$ & $2.38(487,000)$ & 0.11 & $\mathrm{NS}$ \\
MAST (\%) & $22.7^{4}$ & 0 & 5.0 & $<0.05$ \\
SCC400 (\%) & 9.10 & 8.33 & 7.3 & $\mathrm{NS}$ \\
Anti-HEWL IgG d 21and DTH & $2.05(173,000)$ & $2.19(202,000)$ & 0.11 & $\mathrm{NS}$ \\
SCSAV & $1.87(89,000)$ & $2.10(164,000)$ & 0.08 & 0.06 \\
SCSIR & $2.45(622,000)$ & $2.41(504,000)$ & 0.14 & $\mathrm{NS}$ \\
SCSH & 9.10 & 6.70 & 7.88 & $\mathrm{NS}$ \\
MAST $(\%)$ & 18.1 & 6.67 & 9.4 & $\mathrm{NS}$ \\
SCC400 $\%)$ &
\end{tabular}

${ }^{1} \mathrm{SCSAV}=$ mean of all available SCS records over lactation; SCSIR $=$ mean of SCS records within $\pm 30 \mathrm{~d}$ of the start of the immunization procedure; SCSH = peak SCS record during lactation; MAST = occurrence of at least 1 case of clinical mastitis during lactation; SCC400 = percentage of cows with at least 1 test $>400,000$ cells $/ \mathrm{mL}$ during lactation.

${ }^{2}$ Corresponding SCC (cells $\left./ \mathrm{mL}\right)$.

${ }^{3} \mathrm{NS}=P>0.05$.

${ }^{4} 5$ cows out of 22 high responders had mastitis during second lactation.

${ }^{5} 1$ of 11 high responders and 1 of 15 low responders, had mastitis during second lactation.

al., 2006) and the fact that this would therefore affect their ability to mount a CMIR response.

What is perhaps surprising was the relatively small benefit from crossbreeding with the NR for udder health. However, the incidence of disease was very low. For all udder health traits examined (and IR traits), the NRX cows generally were only marginally more favorable (although not significantly so) compared with the HF. Other data by Begley et al. (2007a) showed a distinct advantage with the crossbred compared with the HF. The latter used data from the wider study ( 46 herds) in first lactation. An examination of the lactation-average SCC during first lactation for these 30 herds reveals mean SCS values (SCC in parentheses) of 2.05 (193,000 cells $/ \mathrm{mL}), 1.91$ (129,000 cells $/ \mathrm{mL})$, and $1.96(131,000$ cells $/ \mathrm{mL}$ ) for HF, NR, and NRX, respectively. Further examination of the data revealed that cows culled for reasons other than reproductive failure had mean SCS (SCC in parentheses) values of 2.18 (484,000 cells $/ \mathrm{mL}$ ), $1.96(236,000$ cells/mL), and $1.92(143,000$ cells $/ \mathrm{mL})$ for $\operatorname{HF}(\mathrm{n}=50), \mathrm{NR}(\mathrm{n}=12)$, and $\operatorname{NRX}(\mathrm{n}=19)$ cows, respectively. Of the cows culled for reasons other than reproductive failure, $19 \%$ of the $\mathrm{HF}, 5 \%$ of the NR, and $6 \%$ of the NRX had mean first-lactation SCC values $>400,000$ cells $/ \mathrm{mL}$. These data suggest that greater culling for poor udder health took place within the HF breed group. Moreover, recent breeding values obtained from the ICBF (February 2008) provide evidence of additive genetic improvement from crossbreeding with the NR with mean health sub-index (weighted $75 \%$ toward udder health and 25\% toward locomotion) values of
$€-1.67, € 4.6, € 1.9$ for HF, NR, and NRX cows, respectively, within these study herds.

Several lines of research have shown that the immune system offers an avenue to increase disease resistance given its role in host defense (Abdel-Azim et al., 2005; Mallard, 2007). Pathogens are either intracellular or extracellular, as defined according to their ability to survive and replicate within host cells. Resistance to each pathogen type involves outcomes of complex innate and adaptive (AMIR and CMIR) host defense mechanisms, but generally AMIR is key to the control of extracellular pathogens, whereas CMIR dominates in control of intracellular pathogens. Together they are measurements of broad-based immunity. Studies carried out on mice have clearly demonstrated that selection solely on AMIR is inversely associated with CMIR and with the control of intracellular pathogens, but not necessarily extracellular pathogens (Biozzi et al., 1979). Therefore, the identification of animals that are high responders for both traits is ideal (Wilkie and Mallard, 1999; Hernandez et al., 2006). In the present study, high and low responders were identified across all breeds with no indication of differences among breed groups. The associations witnessed among SCS or mastitis occurrence and immune responses were inconsistent, whereas previous studies have reported health benefits of high immune responders (Wilkie et al., 1998; Wagter et al., 2000; Mallard, 2007). This may relate to the fact that disease occurrence was low in the current study or perhaps to the fact that the IR was tested outside the peripartum period unlike the previous studies. However, 
although the periparturient period does present greater metabolic and physical challenges to the dairy cow compared with later lactation (Quinn-Whelton et al., 2007), it is expected that cows that mount an effective IR during the peripartum period would also quite readily mount an IR in mid-lactation; that is, high IR cows are expected to be high IR response cows irrespective of when the IR measurement takes place. Although we are unaware of published repeatability estimates for IR traits, available estimates of heritability (Hernandez et al., 2006) suggest that moderate to high repeatability is likely. Recent studies from 875 peripartum cows clearly showed beneficial associations between both AMIR and CMIR with disease, particularly mastitis and ketosis (Hernandez, 2007; De La Paz, 2008). However, results in non-periparturient cows in which disease incidence was lower were inconsistent (Hernandez, 2007).

\section{CONCLUSIONS}

The study highlights the superiority of the NR breed with regard to udder health. It also provides some evidence regarding the fact that crossbreeding with the NR will improve udder health compared with the HF. Differences in primary AMIR to the test antigen HEWL, particularly the increase in IgG, in favor of the NR were also noted. However, the IR traits investigated proved to be inconsistent indicators of udder health.

\section{ACKNOWLEDGMENTS}

The authors acknowledge the financial support of Research Stimulus Fund (RSF-06-353). The technical assistance of Billy Curtin (Teagasc, Moorepark) and the contribution of University College Dublin placement students at Moorepark is also acknowledged. This study would not have been possible without the participation of the 30 commercial dairy farmers. The authors acknowledge their cooperation in relation to access to their dairy herds and to their farm records.

\section{REFERENCES}

Abdel-Azim, G. A., A. E. Freeman, M. E. Kehrli Jr., S. C. Kelm, J. L. Burton, A. L. Kuck, and S. Schnell. 2005. Genetic basis and risk factors for infectious and non-infectious diseases in US Holsteins. I. Estimation of genetic garameters for single diseases and general health . J. Dairy Sci. 88:1199-1207.

Auldist, M. J., S. Coats, G. L. Rogers, and G. H. McDowell. 1995. Changes in the composition of milk from healthy and mastitic dairy cows during lactation cycle. Aust. J. Exp. Agric. 35:427436.

Begley, N., F. Buckley, E. Burnside, L. Schaeffer, M. Rath, and B. A. Mallard. 2007b. Comparison of Immune Response in HolsteinFriesian and Holstein-Friesian $\times$ Norwegian Red calves on Canadian farms. Page 63 in Proc. Agric. Res. Forum, Tullamore, Co. Offaly, Ireland. Standard Printers, Galway, Ireland.
Begley, N., M. Rath, and F. Buckley. 2007a. Milk production, udder health, body condition score at breeding and fertility of first lactation Holstein-Friesian, Norwegian Red and Holstein-Friesian $\times$ Norwegian Red cows on Irish dairy farms. Page 314 in 58th Meeting European Association for Animal Production, Dublin, Ireland. Wageningen Acad. Publ., Wageningen, the Netherlands.

Berry, D. P., and P. R. Amer. 2005. Derivation of a health sub-index for the economic Breeding Index in Ireland. Technical report to the Irish Cattle Breeding Federation (August). http://www.icbf.com/ publications/files/Derivation_of_health_sub-index_with_loco.doc Accessed May 5, 2007.

Berry, D. P., B. L. Harris, A. M. Winkleman, and W. Montgomerie. 2005. Phenotypic associations between traits other than production and longevity in New Zealand dairy cattle. J. Dairy Sci. 88:29622974.

Biozzi, G., D. Mouton, A. Heuman, Y. Bouthillier, C. Stiffel, and J. C. Mevel. 1979. Genetic analysis of antibody responsiveness to sheep erythrocytes in crosses between lines of mice selected for high or low antibody synthesis. Immunology 36:427-438.

De La Paz, J. 2008. Using antibody and cell-mediated immune response to test antigens in periparturient dairy cows as a measure of disease resistance. MS Thesis. University of Florida, Gainesville.

Green, M. J., L. E. Green, Y. H. Schukken, A. J. Bradley, E. J. Peeler, H. W. Barkema, Y. de Haas, V. J. Collis, and G. F. Medley. 2004. Somatic cell count distributions during lactation predict clinical mastitis. J. Dairy Sci. 87:1256-1264.

Hansen, M., M. S. Lund, M. K. Sorensen, and L. G. Christensen 2002. Genetic parameters of dairy character, protein yield, clinical mastitis, and other diseases in the Danish Holstein cattle. J. Dairy Sci. 85:445-452.

Heringstad, B., G. Klemetsdal, and J. Ruane. 1999. Clinical mastitis in Norwegian cattle: Frequency, variance components and genetic correlation with protein yield. J. Dairy Sci. 82:1325-1330.

Heringstad, B., G. Klemetsdal, and J. Ruane. 2000. Selection for mastitis resistance in dairy cattle: A review with focus on the situation in the Nordic countries. Livest. Prod. Sci. 64:95-106.

Heringstad, B., R. Rekaya, D. Gianola, G. Klemetsdal, and K. A. Weigel. 2003. Genetic change for clinical mastitis in Norwegian cattle: A threshold model analysis. J. Dairy Sci. 86:369-375.

Hernandez, A. 2007. Phenotypic and genetic parameters of acquired immune response to improve dairy cattle health. $\mathrm{PhD}$ thesis. University of Guelph, Guelph, Ontario, Canada.

Hernandez, A., N. Karrow, and B. A. Mallard. 2003. Evaluation of immune responses of cattle as a means to identify high or low responders and use of a human microarray to differentiate gene expression. Genet. Sel. Evol. 35(Suppl. 1):S67-S81.

Hernandez, A., V. M. Quinton, F. Miglior, and B. A. Mallard. 2006. Genetic parameters of dairy cattle immune response traits. 8th World Congress on Genetics Applied to Livestock Production, Belo Horizonte, MG, Brazil. http://www.wcgalp8.org.br/wcgalp8/ articles/paper/15_459-1625.pdf

Hernandez, A., J. A. Yager, B. N. Wilkie, K. E. Leslie, and B. A. Mallard. 2005. Evaluation of bovine cutaneous delayed-type hypersensitivity (DTH) to various test antigens and a mitogen using several adjuvants. Vet. Immunol. Immunopathol. 104:4558.

Mallard, B. A. 2007. Immunology and Genetics: Phenotypic, genetic and epigenetic variation of bovine immune response and disease resistance. Proc. 40th Annu. Conf. Am. Assoc. Bovine Pract., Vancouver, BC, Canada. Am. Assoc. Bovine Pract., Auburn, AL

Mallard, B. A., K. E. Leslie, J. C. M. Dekkers, R. Hedge, M. Bauman, and M. J. Stear. 1995. Differences in bovine lymphocyte antigen associations between immune responsiveness and risk of disease following intramammary infection with Staphylococcus aureus. J. Dairy Sci. 78:1937-1944.

Mallard, B. A., B. N. Wilkie, B. W. Kennedy, and M. Quinton. 1992. Use of estimated breeding values in a selection index to breed Yorkshire pigs for high and low immune and innate resistance factors. Anim. Biotechnol. 3:257-280. 
Miglior, F., B. L. Muir, and B. J. van Doormal. 2005. Selection indices in Holstein cattle of various countries. J. Dairy Sci. 88:12551263.

Olori, V. E., and J. B. Galesloot. 1999. Projection of partial lactation records and calculation of 305-day yields in the Republic of Ireland. Proc. 1999 Interbull Mtg., Zurich, Switzerland. Interbull, Uppsala, Sweden.

Pinard, M. H., J. A. M. van Arendonk, M. G. B. Nieuwland, and A. J. van der Zijpp. 1993. Divergent selection for humoral immune responsiveness in chickens: Distribution and effect of major histocompatibility complex types. Genet. Sel. Evol. 25:191-203.

Quinn-Whelton, N., L. Killen, T. Guinee, and F. Buckley. 2007. Detection of abnormal recordings in Irish milk recorded data. Ir. J. Agric. Food Res. 46:117-127.

Rupp, R., and D. Boichard. 1999. Genetic parameters for clinical mastitis, somatic cell score, production, udder type traits and milking ease in first lactation Holsteins. J. Dairy Sci. 82:21982204.

SAS Institute. 2006. User's Guide: Statistics. SAS Institute Inc., Cary, NC.

Wagter, L. C., B. A. Mallard, B. N. Wilkie, K. E. Leslie, P. J. Boettcher, and J. C. M. Dekkers. 2000. A quantitative approach to classifying Holstein cows based on antibody responsiveness and its relationship to peripartum mastitis occurrence. J. Dairy Sci. 83:488-498.

Wagter, L. C., B. A. Mallard, B. N. Wilkie, K. E. Leslie, P. J. Boettcher, and J. C. M. Dekkers. 2003. The relationship between milk production and antibody response to ovalbumin during the peripartum period. J. Dairy Sci. 86:169-173.

Walsh, S., F. Buckley, D. P. Berry, K. Pierce, N. Byrne, and P. Dillon. 2007. Effect of breed, feeding system and parity on udder health and milking characteristics. J. Dairy Sci. 90:5767-5779.

Walsh, S., F. Buckley, K. Pierce, N. Byrne, J. Patton, and P. Dillon. 2008. Effects of breed and feeding system on milk production bodyweight, body condition score, reproductive performance and postpartum ovarian function. J. Dairy Sci. 91:4401-4413.

Wilkie, B., and B. Mallard. 1999. Selection for high immune response: An alternative approach to animal health maintenance? Vet. Immunol. Immunopathol. 72:231-235.

Wilkie, B. N., B. A. Mallard, M. Quinton, and J. Gibson. 1998. Multitrait selection for immune response: A possible alternative strategy for enhanced livestock health and productivity. Pages 29-38 in Progress in Pig Science. J. Wiseman, M. A. Varley, and J. P. Chadwick, ed. Nottingham University Press, Loughborough, UK. 